\title{
Perfil de Suscetibilidade Aos Antimicrobianos de Cepas de Escherichia coli Isoladas de Fezes de Suínos da Região Sul
}

\section{Leisiane Valbring (I), Juliete Gomes de Lara de Souza (II), Taise da Silva (II)}

(I) FAG - Faculdade Assis Gurgacz (Avenida das Torres, 500 - Loteamento FAG - Cascavel Paraná), (II) UNIOESTE - Universidade Estadual do Oeste do Paraná (Rua Universitária, 2069 Jardim Universitário - Cascavel - Paraná)

\section{Resumo}

A produção de carne suína no Brasil existe desde os primórdios da nossa civilização e consolidou-se como a mais importante fonte de proteína animal do mundo após 1978. O crescimento do país como exportador da carne suína está diretamente relacionado aos altos índices de produtividade e qualidade do produto, com a adequação às exigências dos diferentes mercados importadores. Nos últimos tempos houve mudanças na criação de suínos, isso porque ocorreram modificações tecnológicas que buscam reduzir os custos e aumentar a escala de produção, no entanto, as principais enfermidades que afetam os rebanhos suínos continuam preocupantes. Entre os principais patógenos de importância na suinocultura destaca-se a Escherichia coli, uma bactéria que coloniza diferentes hospedeiros e é amplamente distribuída no meio ambiente. Diante deste contexto o presente trabalho teve por objetivo verificar o perfil de suscetibilidade de cepas de E.coli em amostras entéricas, processadas em um laboratório veterinário da cidade de Cascavel - PR, durante o período de janeiro de 2011 a julho de 2013. E.coli foi isolada em 623 amostras entéricas. Para estas amostras foram testados os seguintes antimicrobianos: apramicina, ceftiofur, ciprofloxacina, florfenicol, gentamicina, espectinomicina/lincomicina, sulfaclorpiridazina/trimetoprima, neomicina e sulfametoxazol/trimetoprim. A metodologia utilizada foi a de disco-difusão de acordo com os critérios recomendados pelo Clinical and Laboratory Standards Institute (CLSI). As 
cepas apresentaram resistência para apramicina, florfenicol, sulfaclorpiridazina/trimetoprima e sulfametoxazol/trimetoprim, contudo, a gentamicina foi sensível durante os três anos analisados. Os resultados deste estudo sugerem o uso prudente dos antimicrobianos, buscando desta maneira reduzir a multirresistência e minimizar a disseminação de cepas resistentes que são agentes de doenças transmitidas por alimentos em seres humanos.

Palavras-Chave: antimicrobianos, Escherichia coli, suscetibilidade, suinocultura

\section{Agência de Fomento:}

